\title{
Pozisyonel obstrüktif uyku apne hipopne sendromunda hasta profili
}

\author{
Patient profile in positional obstructive sleep apnea-hypopnea syndrome
}

\author{
Ahmet Volkan Sunter ${ }^{1}$, Ela Araz Server ${ }^{1}\left(\mathbb{D}\right.$, Özgür Yiğit $^{1}{ }^{\circledR}$, Özlem Önerci Çelebi1 ${ }^{1}$, \\ Muhammet Yıldız'D, Özlem Uzman ${ }^{3}$ (D) \\ ${ }^{1}$ İstanbul Ĕgitim ve Araştırma Hastanesi, Kulak Burun Boğaz Kliniği, İstanbul, Türkiye \\ ${ }^{2}$ Rize Devlet Hastanesi Kulak Burun Boğaz Kliniği, Rize, Türkiye \\ ${ }^{3}$ İstanbul Eğitim ve Araştırma Hastanesi Göğüs Hastalıkları Kliniği, İstanbul, Türkiye
}

\section{$\ddot{O} Z$}

Amaç: Bu çalışmada obstrüktif uyku apne hipopne sendromu (OUAHS) olan hasta nüfusunda pozisyonel OUAHS (P-OUAHS) insidansı ve hasta profili araştırıldı.

Hastalar ve Yöntemler: Uyku laboratuvarında Ocak 2016-Aralık 2017 tarihleri arasında polisomnografi (PSG) testi yapılan 161 hastanın (134 erkek, 27 kadın; ort. yaş 49 yıl; dağılım, 32-65 yıl) dosyaları retrospektif olarak tarandı. Cinsiyet, yaş, boy, kilo, vücut kütle indeksi (VKİ), boyun çevresi ölçümleri ve PSG testi verileri kaydedildi. Hastalar P-OUAHS ve non-pozisyonel OUAHS (NonP-OUAHS) olarak iki gruba ayrıldı.

Bulgular: Pozisyonel OUAHS hastaları OUAHS tanısı konulan tüm hastaların \%41.6'sını oluşturdu. P-OUAHS grubunun kadın cinsiyet oranı NonP-OUAHS grubuna kıyasla istatistiksel olarak anlamlı şekilde düşüktü (\%6'ya karşı \%24.5; p=0.002). P-OUAHS grubunun VKİ ortalaması NonP-OUAHS grubuna kıyasla istatistiksel olarak anlamlı şekilde düşüktü $(\mathrm{p}=0.002)$. Gruplar arasında boyun çevresi ortalamalarında istatistiksel olarak anlamlı farklılık saptanmadı $(\mathrm{p}=0.708)$. Apne hipopne indeksi (AHI) ortalaması P-OUAHS grubunda istatistiksel olarak anlamlı şekilde daha düşüktü $(\mathrm{p}<0.001)$.

Sonuç: OUAHS hastalarının \%41.6'sı P-OUAHS hastası idi. Pozisyonel OUAHS hastalarının VKI ve AHI değerleri NonP-OUAHS hastalarından daha düşüktü.

Anahtar sözcükler: Apne hipopne indeksi; vücut kitle indeksi; polisomnografi; pozisyonel obstrüktif uyku apne hipopne sendromu.

\begin{abstract}
Objectives: This study aims to investigate the incidence of positional obstructive sleep apnea-hypopnea syndrome (P-OSAHS) and patient profile in OSAHS patient population.

Patients and Methods: Files of 161 patients (134 males, 27 females; mean age 49 years; range, 32 to 65 years) who underwent polysomnography (PSG) test between January 2016 and December 2017 in a sleep laboratory were retrospectively screened. Gender, age, height, weight, Body Mass Index (BMI), neck circumference measurements and PSG test data were recorded. Patients were divided into two groups as P-OSAHS and non-positional OSAHS (NonP-OSAHS).
\end{abstract}

Results: Patients with P-OSAHS accounted for $41.6 \%$ of all patients diagnosed with OSAHS. The female gender ratio of P-OSAHS group was statistically significantly lower than NonP-OSAHS group ( $6 \%$ vs. $24.5 \% ; \mathrm{p}=0.002)$. Mean BMI of P-OSAHS group was statistically significantly lower than NonP-OSAHS group $(\mathrm{p}=0.002)$. No statistically significant difference was detected in the neck circumference averages between the groups $(\mathrm{p}=0.708)$. Mean apnea-hypopnea index (AHI) was statistically significantly lower in the P-OSAHS group $(\mathrm{p}<0.001)$.

Conclusion: Of the OSAHS patients, $41.6 \%$ were P-OSAHS patients. The BMI and AHI values of P-OSAHS patients were lower than NonP-OSAHS patients.

Keywords: Apnea-hypopneaindex; body massindex; polysomnography; positional obstructive sleep apnea-hypopnea syndrome.

\section{Geliş tarihi: 11 Ağustos 2018 Kabul tarihi: 20 Eylül 2018}

İletişim adresi: Dr. Ela Araz Server. İstanbul Eğitim ve Araştırma Hastanesi, Kulak Burun Boğaz Kliniği, 34098 Fatih, İstanbul, Türkiye. e-posta: serverela@hotmail.com

\section{Atıf:}

Sunter AV, Araz Server E, Yiğit Ö, Önerci Çelebi Ö, Yıldız M, Uzman Ö. Pozisyonel obstrüktif uyku apne hipopne sendromunda hasta profili. KBB Uygulamaları 2019;7(1):19-24. 
Obstrüktif uyku apne hipopne sendromu (OUAHS) uyku sırasında üst hava yolunun tekrarlayan tam veya kısmi tıkanma epizodları ile seyreden hastalığıdır. ${ }^{[1]}$ Obstrüktif uyku apne hipopne sendromu tanısında altın standart polisomnografi (PSG)'dir. Polisomnografide Apne Hipopne İndeksi (AHİ'nin 5'den büyük bulunması OUAHS tanısını koydurur. Obstrüktif uyku apne hipopne sendromu, PSG kriterlerine göre pozisyonel OUAHS (P-OUAHS) ve non-pozisyonel OUAHS (NonP-OUAHS) olarak sinıflandirılmaktadır. Pozisyonel OUAHS, AHİ 5'den büyük olan bir olguda, nonsupin-AHİ'nin normal sınırlarda (<5) olması şartıyla, supin-AHİ'nin nonsupin-AHİ'den en az iki kat veya daha fazla olması olarak tanımlanmaktadır. ${ }^{[2]}$ Tüm OUAHS hastalarının \%50'sinden fazlasını P-OUAHS oluşturur. ${ }^{[3-5]}$ Pozisyonel OUAHS ve NonP-OUAHS hasta profillerinin farklarını gösteren birçok çalışma vardır. Bu çalışmalarda sonuçlar farklı olsa da P-OUAHS hastalarının daha genç olduğu ve NonP-OUAHS olan hastalara kıyasla vücut kütle indeks (VKİ'lerinin ve AHİ seviyelerinin daha düşük olduğu gösterilmiştir. ${ }^{[3,5,6]}$

Obstrüktif uyku apne hipopne sendromunda sürekli pozitif hava yolu basıncı (CPAP) en etkili tedavi yöntemidir. Ayrıca uyku hijyenin sağlanması, oral cihazlar, kilo verme, pozisyonel tedavi ve üst solunum yolu cerrahisi gibi birçok farklı tedavi seçenekleri de vardır. Tedavinin kişiselleştirilmesi OUAHS'nin tedavi başarısını artırır. ${ }^{[7]}$ Örneğin P-OUAHS hastaları basit pozisyon tedavilerinden ya da pozisyonlandırma cihazlarından fayda görebilirken, NonP-OUAHS hastaları CPAP ya

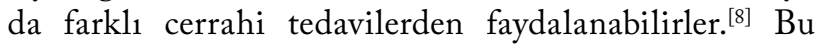
nedenle hastaların P-OUAHS ayırıcı tanısının doğru tanı yöntemi ile ve en kısa sürede konulması ve hastaya uygun tedavinin planlanması önem arz etmektedir. Türk toplumunda P-OUAHS insidansını ve hasta profilini araştıran çalışma bulunmamaktadır. Biz çalışmamızda hitap ettiğimiz hasta nüfusunda P-OUAHS insidansını ve P-OUAHS hastaları için en iyi ayrımı yapacak potansiyel faktörleri tanımlamayı amaçladık.

\section{HASTALAR VE YÖNTEMLER}

Uyku laboratuvarında Ocak 2016 - Aralık 2017 tarihleri arasında yapılan PSG çalışmaları ve hastaların dosyalar1 retrospektif olarak tarand. Santral apnesi ve ek nörolojik hastalığ 1 olanlar, AHİ $<5$ olanlar, pozisyon sensörü herhangi bir nedenle çalışmayanlar (bilinmeyen $>\% 10$ ), toplam uyku süresinin \%10'undan daha az bir süre supin veya lateral pozisyonda kalmış olan hastalar çalışmaya dahil edilmedi. Hastalar Amerikan Uyku Tibbı Akademisi kriterlerine göre P-OUAHS ve NonP-OUAHS olarak iki gruba ayrıldı. Dosyalardan cinsiyet, yaş, boy, kilo, VKİ, krikoid kartilaj hizasından yapılan boyun çevresi ölçümleri kaydedildi. Çalışmanın etik kurul onayı İstanbul Eğitim ve Araştırma Hastanesi Etik Kurulundan alındı. Çalışmaya katılan bireyler çalışma hakkında bilgilendirildi ve bilgilendirilmiş hasta onamları alındı. Çalışma Helsinki Deklarasyonu ilkelerine uygun olarak gerçekleştirildi.

\section{Polisomnografi tetkiki}

Çalışmaya alınan tüm hastalara bir gece uyku laboratuvarında PSG cihazı (EMBLA ${ }^{\mathrm{TM}}$ Digital System 17 channels, Kanata, Ontario, Canada) ile testleri yapild. Test sırasında; dört elektroensefalografi (EEG) kanalı (C3-A2, C4-A1, O1-A2, O2-A1), iki elektrookülogram (EOG) (LOC-A2, ROC-A1), bir çene altı ve iki tarafl 1 tibial elektromiyogramlar, elektrokardiyografi (EKG), hava akımı (nazal kanül ya da nazal-oral termistör ile), vücut pozisyonu, solunum eforu (torakal ve abdominal piezoelektrik kemerlerle), arteriyel oksihemoglobin satürasyonu (parmak ucundan, pulseoksimetre cihazı ile) ölçümü yapıldı. Bütün veriler, uyku süresince video kayitlarıyla birlikte, bilgisayarlı PSG sisteminde (RemLogic Software) topland ve otomatik olarak skorland1. Uyanıklik, REM (Rapid Eye Movement) ve non-REM solunum sayıları hesapland. Apne ve hipopneler değerlendirilerek AHİ saptand. Obstrüktif, miks ve santral apneler Amerikan Uyku Tibbı Akademisi kriterlerine göre belirlendi. Hipopneler, uyku sırasında 10 sn'den uzun süren, oksijen satürasyonunda $\geq \% 3$ düşüşe yol açan, bazal değere göre tidal volümde $\geq \% 50$ azalma olarak tanımland. Apne ve hipopne indeksi uyku süresince izlenen apne ve hipopnelerin saatlik ortalaması olarak alınd. Apne ve hipopne indeksi $\geq 5$ ise OUAHS varlığ hafif OUAHS, $15 \geq$ AHI $<30$ olanlar orta OUAHS ve AHİ $\geq 30$ olan hastalar ağır OUAHS olarak belirlendi. Pozisyonel -OUAHS, OUAHS tanısı konan (total-AHİ >5) bir olguda, nonsupin-AHİ'nin normal sinırlarda olması (<5) şartıyla, supin-AHİ'nin nonsupin-AHİ'den en az iki kat veya daha fazla olması durumu olarak belirlendi.

Polisomnografi kayıtlarındaki veriler kullanılarak hastaların AHİ, supin-AHİ, nonsupin-AHİ, uyku kalitesi (\%), horlama zamanı (\%), uyku periyodu (\%) (N1, N2, N3, R, Wake), ortalama apne ve hipopne istatistikleri, ortalama oksijen satürasyonu, en düşük oksijen satürasyonu, ortalama desatürasyon, REM ortalama oksijen satürasyonu, Non-REM ortalama oksijen satürasyonu ve uyku esnasındaki pozisyon bilgileri incelendi. Pozisyonel OUAHS ve NonP-OUAHS olarak iki gruba ayrılan hastaların tüm parametreleri karşılaştırıld.

\section{İstatistiksel analiz}

İstatistiksel analizler Windows için SPSS 15.0 versiyon (SPSS, Inc., Chicago, IL, USA) paket programı 


\section{Tablo 1}

P-OUAHS ve NonP-OUAHS hastalarının demografik özellikleri, vïcut kütle indeksleri ve boyun çevrelerinin kıyaslanması

\begin{tabular}{|c|c|c|c|c|c|c|c|c|c|}
\hline & \multicolumn{4}{|c|}{ P-OUAHS $(n=67)$} & \multicolumn{4}{|c|}{ NonP-OUAHS $(n=94)$} & \multirow[b]{2}{*}{$p$} \\
\hline & Say1 & Yüzde & Ort. \pm SS & Ortanca & Say1 & Yüzde & Ort. \pm SS & Ortanca & \\
\hline Cinsiyet & & & & & & & & & 0.002 \\
\hline Erkek & 63 & 94.0 & & & 71 & 75.5 & & & \\
\hline Kadın & 4 & 6.0 & & & 23 & 24.5 & & & \\
\hline Yaş (yıl) & & & $49.3 \pm 10.4$ & 49 & & & $47.6 \pm 11.2$ & 48 & 0.347 \\
\hline VKİ & & & $28.9 \pm 3.9$ & 29 & & & $30.9 \pm 4.3$ & 30.3 & 0.002 \\
\hline Boyun çevresi $(\mathrm{cm})$ & & & $41.9 \pm 3.1$ & 42 & & & $41.5 \pm 3.1$ & 42 & 0.708 \\
\hline
\end{tabular}

kullanılarak yapıldı. Tanımlayıcı istatistikler; kategorik değişkenler için sayı ve yüzde, sayısal değişkenler için ortalama, standart sapma, ortanca olarak verildi. Bağımsız iki grup arası karşılaştırmalar sayısal değişkenler normal dağ $\breve{l l}_{1}$ koşulunu sağladı̆̆ koşulda Student $t$ test ile, sağlamadığ 1 koşulda Mann-Whitney U testi ile yapıldı. Kategorik değişkenlerin bağımsız gruplarda oranları Ki-kare analizi ile karşılaştırıldı. Belirleyici faktörler için

\begin{tabular}{|c|c|c|c|c|c|}
\hline & \multicolumn{2}{|c|}{ P-OUAHS $(n=67)$} & \multicolumn{2}{|c|}{ NonP-OUAHS $(\mathrm{n}=94)$} & \multirow[b]{2}{*}{$p$} \\
\hline & Ort. \pm SS & Ortanca & Ort. \pm SS & Ortanca & \\
\hline Supin & $50.1 \pm 20.6$ & 50.0 & $43.4 \pm 22.5$ & 40.2 & 0.055 \\
\hline Nonsupin & $49.8 \pm 20.6$ & 50.0 & $56.3 \pm 22.4$ & 58.8 & 0.064 \\
\hline AHİ supin & $28.9 \pm 22.4$ & 20.7 & $45.0 \pm 29.8$ & 39.9 & $<0.001$ \\
\hline AHİ nonsupin & $2.1 \pm 1.4$ & 1.8 & $48.6 \pm 50.1$ & 33.8 & $<0.001$ \\
\hline AHİ supin/AHİ nonsupin & $23.6 \pm 36.8$ & 10.6 & $2.1 \pm 2.6$ & 1 & $<0.001$ \\
\hline AHİ & $13.3 \pm 7.3$ & 11.5 & $33.3 \pm 25.1$ & 24.9 & $<0.001$ \\
\hline Uyku etkinliği (\%) & $88.6 \pm 8.4$ & 91.2 & $86.3 \pm 12.8$ & 89.2 & 0.381 \\
\hline Horlama süresi & $11.6 \pm 14.3$ & 5.6 & $12.2 \pm 15.8$ & 5.5 & 0.969 \\
\hline Non-REM 1 & $10.4 \pm 8.3$ & 7.5 & $12.8 \pm 8.8$ & 11.1 & 0.022 \\
\hline Non-REM 2 & $53.0 \pm 12.8$ & 54.0 & $59.0 \pm 15.6$ & 59.6 & 0.010 \\
\hline Non-REM 3 & $15.3 \pm 10.8$ & 13.7 & $10.5 \pm 8.1$ & 9.9 & 0.005 \\
\hline REM & $13.0 \pm 7.3$ & 12.8 & $7.6 \pm 6.1$ & 7.2 & $<0.001$ \\
\hline Apne & $17.5 \pm 5.9$ & 16.4 & $18.7 \pm 6.7$ & 18.6 & 0.029 \\
\hline Uyanıklık & $8.3 \pm 7.6$ & 6.4 & $10.3 \pm 11.5$ & 7.6 & 0.373 \\
\hline Hipopne & $23.5 \pm 6.5$ & 21.8 & $23.9 \pm 4.6$ & 23.0 & 0.132 \\
\hline Göreceli horlama & $11.6 \pm 14.3$ & 5.6 & $12.2 \pm 15.8$ & 5.5 & 0.969 \\
\hline Ortalama $\mathrm{O}_{2}$ & $95.0 \pm 1.4$ & 94.9 & $93.9 \pm 2.5$ & 94.5 & 0.005 \\
\hline En düşük $\mathrm{O}_{2}$ & $85.6 \pm 4.8$ & 86.0 & $80.8 \pm 8.0$ & 83.0 & $<0.001$ \\
\hline $\mathrm{REM} \mathrm{O}_{2}$ & $95.1 \pm 1.6$ & 95.4 & $93.4 \pm 4.1$ & 94.6 & 0.003 \\
\hline Non-REM O${ }_{2}$ & $94.8 \pm 1.3$ & 94.9 & $94.0 \pm 2.3$ & 94.6 & 0.029 \\
\hline Ortalama desatürasyon & $5.2 \pm 1.3$ & 4.9 & $6.3 \pm 2.8$ & 5.7 & 0.001 \\
\hline
\end{tabular}




\begin{tabular}{|c|c|c|c|c|}
\hline \multicolumn{3}{|c|}{ P-OUAHS'yi belirleyen risk faktörleri } & \multirow{2}{*}{\multicolumn{2}{|c|}{$\% 95$ GA }} \\
\hline & $p$ & Ortalama & & \\
\hline \multicolumn{5}{|l|}{ Cinsiyet } \\
\hline Erkek & 0.003 & 7.516 & 1.953 & 28.930 \\
\hline Apne hipopne indeksi & $<0.001$ & 0.890 & 0.846 & 0.936 \\
\hline REM & 0.004 & 1.102 & 1.031 & 1.178 \\
\hline Ortalama desatürasyon & 0.033 & 1.584 & 1.037 & 2.421 \\
\hline
\end{tabular}

Lojistik Regresyon analizi kullanıldı. İstatistiksel alfa anlamlılık seviyesi $\mathrm{p}<0.05$ olarak kabul edildi.

\section{BULGULAR}

Çalışmaya 94 (\%58.4) NonP-OUAHS ve 67 (\%41.6) P-OUAHS olmak üzere toplam 161 hasta dahil edildi. Pozisyonel OUAHS hastalarının yaş ortalaması $49.3 \pm 10.4$ yıl ve NonP-OUAHS hastalarının yaş ortalaması $47.6 \pm 11.2$ yıl olarak hesaplandi. Grupların yaş ortalamaları arasında istatistiksel olarak anlamlı fark yoktu ( $\mathrm{p}=0.347)$. Pozisyonel OUAHS olan hastaların 63'ü (\%94) erkek dördü (\%6) kadındı. NonP-OUAHS olan hastaların 71'i (\%75.5) erkek, 23'ü (\%24.5) kadındı. Pozisyonel OUAHS hastalarının kadın cinsiyet oranı NonP-OUAHS hastalarına kıyasla istatistiksel olarak anlamlı düşüktü (\%6 vs. \%24.5 p=0.002). Pozisyonel OUAHS grubunun VKİ ortalamasi NonP-OUAHS grubuna kiyasla istatistiksel olarak anlamlı düşüktü $(\mathrm{p}=0.002)$. Grupların boyun çevresi ortalamalarında istatistiksel olarak anlamlı fark saptanmadi $(\mathrm{p}=0.708)$ (Tablo 1).

Apne ve hipopne indeksi ortalaması P-OUAHS grubunda istatistiksel olarak anlamlı düşüktü $(\mathrm{p}<0.001)$. Grupların uyku etkinliği, horlama süresi ortalamalarında istatistiksel olarak anlaml fark yoktu ( $\mathrm{p}=0.381, \mathrm{p}=0.969)$. Pozisyonel OUAHS grubunda Non-REM 1 ve 2 ortalamaları NonP-OUAHS grubuna göre istatistiksel olarak anlamlı düşük Non-REM 3 ortalaması istatistiksel olarak anlamlı yüksekti ( $\mathrm{p}=0.022, \mathrm{p}=0.010$ ve $\mathrm{p}=0.005)$. Pozisyonel OUAHS grubunda REM ortalamas1 istatistiksel olarak anlamlı yüksek, apne ortalaması ise anlamlı derecede düşüktü $(\mathrm{p}<0.001, \mathrm{p}=0.029)$. Grupların uyanık, hipopne, relatif horlama süreleri ortalamalarında istatistiksel olarak anlaml fark yoktu $(\mathrm{p}=0.373, \mathrm{p}=0.132$ ve $\mathrm{p}=0.969$ ). Pozisyonel OUAHS grubunun ortalama, en düşük, REM, Non-REM $\mathrm{O}_{2}$ ortalamaları NonPOUAHS grubuna kıyasla istatistiksel olarak anlamlı yüksek, desatürasyon ortalaması istatistiksel olarak anlamlı düşük saptand1 $(\mathrm{p}=0.005, \mathrm{p}<0.001, \mathrm{p}=0.003, \mathrm{p}=0.029$ ve $\mathrm{p}=0.001)$ (Tablo 2).
Hastaların yaş, cinsiyet, VKİ düzeyleri, uyku kalitesi, AHİ, horlama süresi, REM, uyanıklık, apne, hipopne, ortalama $\mathrm{O}_{2}$, en düşük $\mathrm{O}_{2}$, ortalama desatürasyondan oluşturulan modelde P-OUAHS'yi belirleyen en önemli faktörler; erkek cinsiyet, AHİ düşüklüğü, REM, ortalama desatürasyon yüksekliği olarak saptand $1 \quad(p=0.003$, $\mathrm{p}<0.001, \mathrm{p}=0.004$ ve $\mathrm{p}=0.033$ ) (Tablo 3).

\section{TARTIŞMA}

Pozisyonel OUAHS insidansını ve hasta profillerini belirlemek için yaptığımız çalışmada hedef kitlemizde OUAHS tanısı konan erişkinlerde P-OUAS'nin prevalansının \%41.6 olduğu, hastaların düşük VKI'li ve çoğunlukla erkek cinsiyette olduğu belirlendi. Ayrıca P-OUAHS hasta grubunun PSG sonuçlarında AHİ düşüklüğü, REM yüksekliği ve desatürasyon ortalaması düşüklüğü saptandı.

Obstrüktif uyku apne hipopne sendromu farkl1 çalışmalarda değişiklik göstermekle birlikte toplumun \%2-26'sını etkileyen bir hastalıktır. Kardiyovasküler hastalık riskinde artı̧, gündüz uykululuk hali, yaşam kalitesinde düşme, trafik ve iş kazaları gibi önemli morbidite ve sosyal sorunlara neden olur. ${ }^{[9,10]}$ Toplumun önemli bir bölümünü etkileyen bu hastalığın tanısı ve tedavisi hem hastanın sağlığ 1 hem de neden olacağ 1 riskleri önlemek açısından önemlidir.

Obstrüktif uyku apne hipopne sendromu, P-OUAHS ve NonP-OUAHS olarak iki gruba ayrilır. Mador ve ark. ${ }^{[2]}$ P-OUAHS, OUAHS tanisı konan (total-AHİ>5) bir olguda, nonsupin-AHİ'nin normal sinirlarda olması (<5) şartıyla, supin-AHİ'nin nonsupin-AHİ'den en az iki kat veya daha fazla olması olarak tanımlamışlar ve çalışmalarında hafif OUAHS'yi \%49.5, orta OUAHS'yi $\% 19.4$ ve ağır OUAHS'yi \%6.4 oranında gördüklerini bildirmişler, Oksenberg ve ark. ${ }^{[11]}$ ise supine respiratory disturbance index (RDI) ile lateral RDI arasindaki oranı $\geq 2$ şeklinde tanımlamışlar ve prevalansını \%55.9 olarak bildirmişlerdir. Teerapraipruk ve ark. ${ }^{[12]} \mathrm{P}$-OUAHS prevalansını literatürün aksine $\% 70$ olarak bildirmişler 
ve bunu Asyalıların batı ırkından daha zayıf olmasına bağlanabileceğini bildirmişlerdir. Di-Tullio ve ark.nın ${ }^{[5]}$ yaptıkları çalışmada ev tipi solunumsal poligrafi cihazıyla yapılan taramada P-OUAHS hastalarının prevalansının uyku laboratuvarlarında yapılan PSG sonuçlarıyla uyumlu olarak \%54.6 olduğunu belirtmişlerdir. Biz çalışmamızda uyku laboratuvarında yapılan PSG yöntemiyle Mador ve ark.nın ${ }^{[2]}$ kullandığ 1 kriterleri kabul ettik ve prevalansı literatürden farklı olarak \% 41.6 olarak bulduk. Bu farkın uyku laboratuvarımızın yoğunluğundan dolayı daha şiddetli olacağını öngördüğümüz OUAHS hastalarına öncelik veriyor olduğumuza bağladık.

Obstrüktif uyku apne hipopne sendromunun tanis1 için gereken zaman önemli bir konudur. Polisomnografi sırasında hastanın bir geceyi uyku laboratuvarında geçirmesi gerekir ve bu durum önemli bir zaman ve kaynak gerektirir. Daha fazla hastaya ulaşma imkanı sağlamak için ev tipi poligrafi cihazları geliştirilmiştir. Di-Tullio ve ark. ${ }^{[5]}$ yaptıkları çalışmada tanı için ev tipi solunumsal poligraf kullanmışlardır. Özellikle daha önce yapılan çalışmalarda PSG ile tanı konulduğu ve PSG sırasında hastaların sirtüstü pozisyonda daha uzun süre yatabileceği ve AHİ'nin hastalığın olduğundan abartılı şekilde çıkabileceği vurgulanmıştır. ${ }^{[11,13]}$ Di-Tullio ve ark., ${ }^{[5]}$ çalışmalarında kullandıkları ev tipi poligrafi cihazı ile PSG laboratuvarında yapılan çalışmalarla benzer sonuçlar bulduklarını belirtmişlerdir.

Pozisyonel OUAHS hastalarının hastalık şiddetleri ve tedavi yaklaşımları NonP-OUAHS hastalarından farklılık gösterir. ${ }^{[12]}$ Pozisyonel OUAHS düşük AHİ ile ilişkilidir ve desatürasyonlar, yüksek oranda horlama, apne ve hipopne neredeyse sadece supin pozisyonda ortaya çıkar. ${ }^{[14]}$ NonP-OUAHS' den farklı olarak da sürekli pozitif hava yolu basıncı (CPAP) ya da cerrahi tedavilerden başka basit pozisyon tedavilerinden ya da pozisyonlandirma cihazlarından fayda görebilirler. Obstrüktif uyku apne hipopne sendromu hastalarının tedavilerinin doğru planlanması için hastaları kişiselleştirmek önemlidir.

Pozisyonel OUAHS'nin klinik ve demografik özelliklerini karşılaştıran çeşitli çalışmalar vardır. Mador ve ark. ${ }^{[2]} \mathrm{P}$-OUAHS ve NonP-OUAHS arasında yaş, cinsiyet, VKİ ve Epworth Uykululuk Skalası (EUS) arasında fark bulamamışen, NonP-OUAHS'de boyun çevresinin daha geniş olduğunu ve uyku apnesinin daha şiddetli olduğunu bildirmişlerdir. Teerapraipruk ve ark. ${ }^{[12]}$ ise AHİ ve boyun çevresinin P-OUAHS hastalarında daha düşük olduğunu belirtmişler. Ancak Oksenberg ${ }^{[3]}$ ve Güven ${ }^{[15]}$ yaptıkları çalışmalarda P-OUAHS hastalarının daha genç olduklarını, düşük VKİ ve EUS ile ilişkili olduğunu bildirmişlerdir. Oulhaj ve ark. ${ }^{[6]}$ ise P-OUAHS hastalarının daha genç, daha az obez ve daha az hipertansif olduklarını ve ayrıca Mallampati skoru, Berlin ve STOP puanlarının da daha az olduğunu bildirmişler. Bizim çalışmamız da VKİ, P-OUAHS'li hastalarda daha düşük iken boyun çevresinde fark yoktu ve kadın cinsiyet oranı NonP-OUAHS hastalarına kıyasla istatistiksel olarak anlamlı düşüktü (\%6 vs. $\% 24.5 \mathrm{p}=0.002$ ).

Pozisyonel OUAHS ve NonP-OUAHS hastalarının PSG raporlarının karşılaştırıldığ vardır. Chung ve ark. ${ }^{[16]}$ P-OUAHS'de hastalığın daha hafif olduğunu, AHİ'nin daha düşük, ortalama $\mathrm{O}_{2}$ 'nin daha yüksek olduğunu, horlama zamanının daha düşük olduğunu bildirmişlerdir. Oksenberg ve ark.nın ${ }^{[14]}$ çalışmasında horlama frekansının daha düşük olduğunu ve bu düşüklüğün öngördürücü değeri olduğunu raporlamışlardır. Bizim çalışmamızda da benzer şekilde P-OUAHS grubunda AHİ, desatürasyon ortalaması daha düşükken ortalama oksijen satürasyonu daha yüksekti.

Yoğun hasta nüfusuna hitap ettiğimiz hastanemize başvuran hastaların uygun tedaviye en kısa sürede ulaşmaları önemlidir. Bu çalışmadan elde edilen sonuçlar P-OUAHS olma ihtimali yüksek olduğu hastaların belirlenmesinde yararlı olabilir. Bu profile sahip hasta gruplarına uyku çalışması için sıra beklerken pozisyonel tedavi önerileri tavsiye edilebilir. Çalışmamızda hastaların diğer hastalıklarını ve mallampati skoru gibi özellikli klinik bulgularını dahil etmemiş olmamız çalışmamızın kisitlilıklarıdır.

Sonuç olarak, pozisyonel OUAHS olan hastaları belirleyen en önemli faktörler erkek cinsiyet, AHİ düşüklüğü, REM ve ortalama desatürasyon yüksekliğidir.

\section{Çıkar çakışması beyanı}

Yazarlar bu yazının hazırlanması ve yayınlanması aşamasında herhangi bir çıkar çakı̧̧ması olmadığını beyan etmişlerdir.

\section{Finansman}

Yazarlar bu yazının araştırma ve yazarlık sürecinde herhangi bir finansal destek almadıklarını beyan etmişlerdir.

\section{KAYNAKLAR}

1. McNicholas WT. Diagnostic criteria for the sleep apnoea syndrome: time for consensus. Eur Respir J 1996;9:634-5.

2. Mador MJ, Kufel TJ, Magalang UJ, Rajesh SK, Watwe V, Grant BJ. Prevalence of positional sleep apnea in patients undergoing polysomnography. Chest 2005;128:2130-7.

3. Oksenberg A, Silverberg DS, Arons E, Radwan H. Positional vs nonpositional obstructive sleep apnea patients: anthropomorphic, nocturnal polysomnographic, and multiple sleep latency test data. Chest 1997;112:629-39.

4. Cartwright R, Ristanovic R, Diaz F, Caldarelli D, Alder G. A comparative study of treatments for positional sleep apnea. Sleep 1991;14:546-52. 
5. Di-Tullio F, Ernst G, Robaina G, Blanco M, Salvado A, Meraldi A, et al. Ambulatory positional obstructive sleep apnea syndrome. Sleep Sci 2018;11:8-11.

6. Oulhaj A, Al Dhaheri S, Su BB, Al-Houqani M. Discriminating between positional and non-positional obstructive sleep apnea using some clinical characteristics. Sleep Breath 2017;21:877-84.

7. Carberry JC, Amatoury J, Eckert DJ. Personalized Management Approach for OSA. Chest 2018;153:74455.

8. Ravesloot MJL, White D, Heinzer R, Oksenberg A, Pépin JL. Efficacy of the new generation of devices for positional therapy for patients with positional obstructive sleep apnea: a systematic review of the literature and meta-analysis. J Clin Sleep Med 2017;13:813-24.

9. Kryger MH. Diagnosis and management of sleep apnea syndrome. Clin Cornerstone 2000;2:39-47.

10. Teerapraipruk B, Chirakalwasan N, Simon R, Hirunwiwatkul P, Jaimchariyatam N, Desudchit T, et al. Clinical and polysomnographic data of positional sleep apnea and its predictors. Sleep Breath 2012;16:1167-72.
11. Oksenberg A, Silverberg DS, Arons E, Radwan H. Positional vs nonpositional obstructive sleep apnea patients: anthropomorphic, nocturnal polysomnographic, and multiple sleep latency test data. Chest 1997;112:629-39.

12. Teerapraipruk B, Chirakalwasan N, Simon R, Hirunwiwatkul P, Jaimchariyatam N, Desudchit T, et al. Clinical and polysomnographic data of positional sleep apnea and its predictors. Sleep Breath 2012;16:1167-72.

13. Cartwright RD. Effect of sleep position on sleep apnea severity. Sleep 1984;7:110-4.

14. Oksenberg A, Gadoth N. Are we missing a simple treatment for most adult sleep apnea patients? The avoidance of the supine sleep position. J Sleep Res 2014;23:204-10.

15. Guven SF, Ciftci B, Lakadamyali H, Ciftci TU. The high dependency of supine position in obstructive sleep apnea. Saudi Med J 2013;34:147-52.

16. Chung JW, Enciso R, Levendowski DJ, Morgan TD, Westbrook PR, Clark GT. Treatment outcomes of mandibular advancement devices in positional and nonpositional OSA patients. Oral Surg Oral Med Oral Pathol Oral Radiol Endod 2010;109:724-31. 